\title{
Transdermal Nicotine Maintenance Attenuates the Subjective and Reinforcing Effects of Intravenous Nicotine, but not Cocaine or Caffeine, in Cigarette-Smoking Stimulant Abusers
}

\author{
Bai-Fang X Sobel', Stacey C Sigmon' and Roland R Griffiths*,1,2 \\ 'Department of Psychiatry and Behavioral Science, Johns Hopkins University School of Medicine, Baltimore, MD, USA; ${ }^{2}$ Department of \\ Neuroscience, Johns Hopkins University School of Medicine, Baltimore, MD, USA
}

\begin{abstract}
The effects of transdermal nicotine maintenance on the subjective, reinforcing, and cardiovascular effects of intravenously administered cocaine, caffeine, and nicotine were examined using double-blind procedures in nine volunteers with histories of using tobacco, caffeine, and cocaine. Each participant was exposed to two chronic drug maintenance phases (2l mg/day nicotine transdermal patch and placebo transdermal patch). Within each drug phase, the participant received intravenous injections of placebo, cocaine ( 15 and $30 \mathrm{mg} / 70 \mathrm{~kg})$, caffeine (200 and $400 \mathrm{mg} / 70 \mathrm{~kg}$ ), and nicotine ( 1.0 and $2.0 \mathrm{mg} / 70 \mathrm{~kg}$ ) in mixed order across days. Subjective and cardiovascular data were collected before and repeatedly after drug or placebo injection. Reinforcing effects were also assessed after each injection with a Drug vs Money Multiple-Choice Form. Intravenous cocaine produced robust dose-related increases in subjective and reinforcing effects; these effects were not altered by nicotine maintenance. Intravenous caffeine produced elevations on several subjective ratings; nicotine maintenance did not affect these ratings. Under the placebo maintenance condition, intravenous nicotine produced robust dose-related subjective effects, with maximal increases similar to the high dose of cocaine; nicotine maintenance significantly decreased the subjective and reinforcing effects of intravenous nicotine. The results of the present study demonstrate that chronic nicotine maintenance produces tolerance to the effects of intravenous nicotine, but does not affect the subjective or reinforcing effects of cocaine or caffeine. Neuropsychopharmacology (2004) 29, 99 I-1003, advance online publication, 10 March 2004; doi: I 0.1038/sj.npp. I 3004 I 5
\end{abstract}

Keywords: nicotine; cocaine; caffeine; human; tolerance; reinforcement

\section{INTRODUCTION}

Nicotine, cocaine, and caffeine are among the most commonly used and abused psychoactive substances. Although all three of these stimulant drugs produce their effects via different receptor sites, there is evidence to suggest that all three produce their stimulant and reinforcing effects through modulation of the dopaminergic system (Garrett and Griffiths, 1997; Koob and Nestler, 1997; Zernig et al, 1997; Fredholm et al, 1999; Di Chiara, 2000). This shared mechanism of action may account for interactions among these three stimulant drugs.

Previous human studies have characterized the acute intravenous effects of nicotine, cocaine, and caffeine as well as the effects of chronic caffeine administration on the intravenous effects of nicotine, cocaine, and caffeine (Rush et al, 1995; Jones et al, 1999, 2003; Garrett and Griffiths,

\footnotetext{
*Correspondence: RR Griffiths, Behavioral Pharmacology Research Unit, Department of Psychiatry and Behavioral Sciences, Johns Hopkins University School of Medicine, 5510 Nathan Shock Drive, Baltimore, MD 21224, USA, Fax: + I 410550 0030, E-mail: rgriff@jhmi.edu Received 05 August 2003; revised 12 December 2003; accepted 16 January 2004

Online publication: 19 January 2004 at http://www.acnp.org/citations/ Npp I 190403353/default.pdf
}

2001). The current research study extends this line of investigation by examining the effects of chronic nicotine maintenance on the acute effects of intravenous nicotine, cocaine, and caffeine.

Interactions between nicotine and cocaine are of interest because, in addition to the shared dopaminergic mechanism of action, epidemiological studies have shown a strong concordance between tobacco and cocaine abuse (Budney et al, 1993; Roll et al, 1996; Wiseman \& McMillan, 1996). For example, smoking is 3.4 times more prevalent in cocaine abusers than in the general population (Budney et al, 1993) and cocaine-dependent individuals who are cigarette smokers report using cocaine more frequently and in greater amounts than those who are not smokers (Roll et al, 1996). Furthermore, experimental studies have shown that cocaine pretreatment increases cigarette smoking rate (Nemeth-Coslett et al, 1986; Higgins et al, 1994b; Roll et al, 1997). In other studies, nicotine pretreatment has been reported to attenuate cocaine-induced subjective effects in recreational cocaine users (Kouri et al, 2001) and to increase cocaine craving in crack cocaine abusers (Reid et al, 1998).

Likewise, interactions between nicotine and caffeine are of interest because of the shared dopaminergic mechanism, as well as epidemiological and experimental observations. 
Epidemiological studies have demonstrated a strong concordance between tobacco and caffeine use (Istvan and Matarazzo, 1984; Swanson et al, 1994), and preclinical and clinical studies have shown that chronic caffeine administration potentiates the stimulant and reinforcing effects of nicotine (Tanda and Goldberg, 2000; Jones and Griffiths, 2003).

Finally, the effect of chronic nicotine maintenance on the effects of nicotine are of interest given the widespread use of nicotine and that chronic nicotine maintenance is a widely used strategy for treatment of cigarette smoking. Although nicotine tolerance in humans has been demonstrated using a variety of methodological approaches, studies have typically used relatively modest nicotine maintenance doses (usually ad libitum smoking) as well as modest nicotine challenge doses (eg smoking a single cigarette, $20 \mu \mathrm{g} / \mathrm{kg}$ nicotine via nasal spray, or $4 \mathrm{mg}$ nicotine via gum) (Perkins, 2002).

The present study was undertaken to examine the effects of chronic nicotine maintenance (transdermal nicotine patch $v s$ placebo patch for 14-25 days) on the subjective and reinforcing effects of intravenously administered nicotine ( 1 and $2 \mathrm{mg} / 70 \mathrm{~kg}$ ), cocaine (15 and $30 \mathrm{mg} / 70 \mathrm{~kg}$ ), and caffeine $(200$ and $400 \mathrm{mg} / 70 \mathrm{~kg})$ in subjects with histories of using all three compounds. Compared to previous research, the study provided a more aggressive evaluation of nicotine tolerance by using a maintenance condition that involved long-term continuous administration of a high dose of nicotine $(21 \mathrm{mg} /$ day for at least 2 weeks) and by testing tolerance with a high intravenous challenge dose of nicotine $(2 \mathrm{mg}$ nicotine injection delivered over $10 \mathrm{~s})$. Because some nicotine tolerance was expected, the intravenous nicotine challenge condition also served as a positive control to compare with the caffeine and cocaine challenge conditions.

\section{METHODS}

\section{Participants}

Participants were adult volunteers recruited through newspaper advertisements, local flyers, and word of mouth. For inclusion in the study, volunteers had to report a recent history of cocaine use, regular caffeine consumption, and daily cigarette smoking. Prior to enrollment, participants were screened for medical problems and drug use via an evaluation which included a medical history, physical examination, electrocardiogram (ECG), laboratory tests of blood chemistry, hematology, blood pressure, urinalysis testing, and assessment for adequate venous access. In addition, a battery of psychiatric instruments was used to screen for psychiatric disorders. Volunteers were excluded from participating if they had an abnormal ECG, hypertension, significant risk factors for heart disease, a history of seizure disorders, any major medical or psychiatric disorder other than cocaine and nicotine dependence, or poor venous access. Female volunteers were excluded if they were pregnant. For all female participants, pregnancy tests were conducted at admission, at weekly intervals, and at study completion.

Participants were informed that the purpose of the study was to learn more about how various drugs administered via the intravenous and transdermal routes affect their mood and their ability to perform various tasks. They were told that they could receive low to moderate doses of various types of drugs, including sedatives (eg alprazolam, diazepam, triazolam, and secobarbital), stimulants (eg caffeine, cocaine, $d$-amphetamine, nicotine), and opioids (eg heroin, morphine, codeine). Participants were told that the transdermal patch and/or the intravenous injections could contain any of the drugs listed above or a placebo (a blank, no drug). This study was approved by the Institutional Review Board of the Johns Hopkins Bayview Medical Center. Each participant provided written consent before beginning the study and was paid for participation.

In all, 16 volunteers signed the consent and participated in one or more sessions. Seven volunteers did not complete the study for the following reasons: one subject dropped out due to current physiological dependence on opioids, and six subjects were discharged or dropped from data analyses due to invalid or incomplete data. Nine subjects (two females and seven males) completed the study; seven were African American, one was Caucasian and one was Native American. All participants had a DSM-IV diagnosis of cocaine dependence (DSM-IV; American Psychiatric Association, 1994). The nine participants ranged in age from 31 to 44 years (mean 38 years) and weighed 51 to $91 \mathrm{~kg}$ (mean $73 \mathrm{~kg}$ ). Individuals reported histories of using cocaine for $0.3-10$ years (mean 4.5 years) and reported using cocaine 10-30 days during the past month (mean 19 days/month). All nine participants reported using cocaine via smoking. All participants reported regular consumption of caffeinecontaining products (eg caffeinated soda and/or coffee), ranging from 46 to $216 \mathrm{mg} /$ day (mean $136 \mathrm{mg} /$ day). All participants also reported smoking tobacco cigarettes, ranging from 7 to 29 years (mean 20.6 years), and the number of cigarettes smoked daily ranged from 11 to 35 (mean 19.3 cigarettes/day). CO readings at screening ranged from 10 to $26 \mathrm{ppm}$ (mean $16 \mathrm{ppm}$ ). In addition to cocaine, caffeine, and nicotine, all subjects reported some occasional use of other drugs, including alcohol $(n=9)$, marijuana $(n=9)$, and heroin $(n=5)$.

\section{Study Design}

This double-blind study was conducted while participants resided for approximately 7 weeks on a 14-bed residential research facility at the Behavioral Pharmacology Research Unit of the Johns Hopkins University School of Medicine.

The study consisted of a total of 15 sessions (see Table 1) and used a within-participant, double-blind design to evaluate the subjective, reinforcing, and physiological effects of intravenous placebo, cocaine $(15,30 \mathrm{mg} / 70 \mathrm{~kg})$, caffeine $(200,400 \mathrm{mg} / 70 \mathrm{~kg})$, and nicotine $(1.0,2.0 \mathrm{mg} / 70 \mathrm{~kg})$ during each of the two phases: a nicotine maintenance phase and a placebo maintenance phase. During the nicotine maintenance phase, participants wore a transdermal nicotine patch delivering $21 \mathrm{mg} /$ day nicotine; during the placebo maintenance phase, participants wore a transdermal placebo patch. Five participants were exposed to the placebo maintenance phase first (sessions 1-7) and then the nicotine maintenance phase (sessions 8-14). 
Table I Experimental Design: a Schematic of the Experimental Design, Including an Example of the Sequence of Drug Conditions for the Experimental Sessions

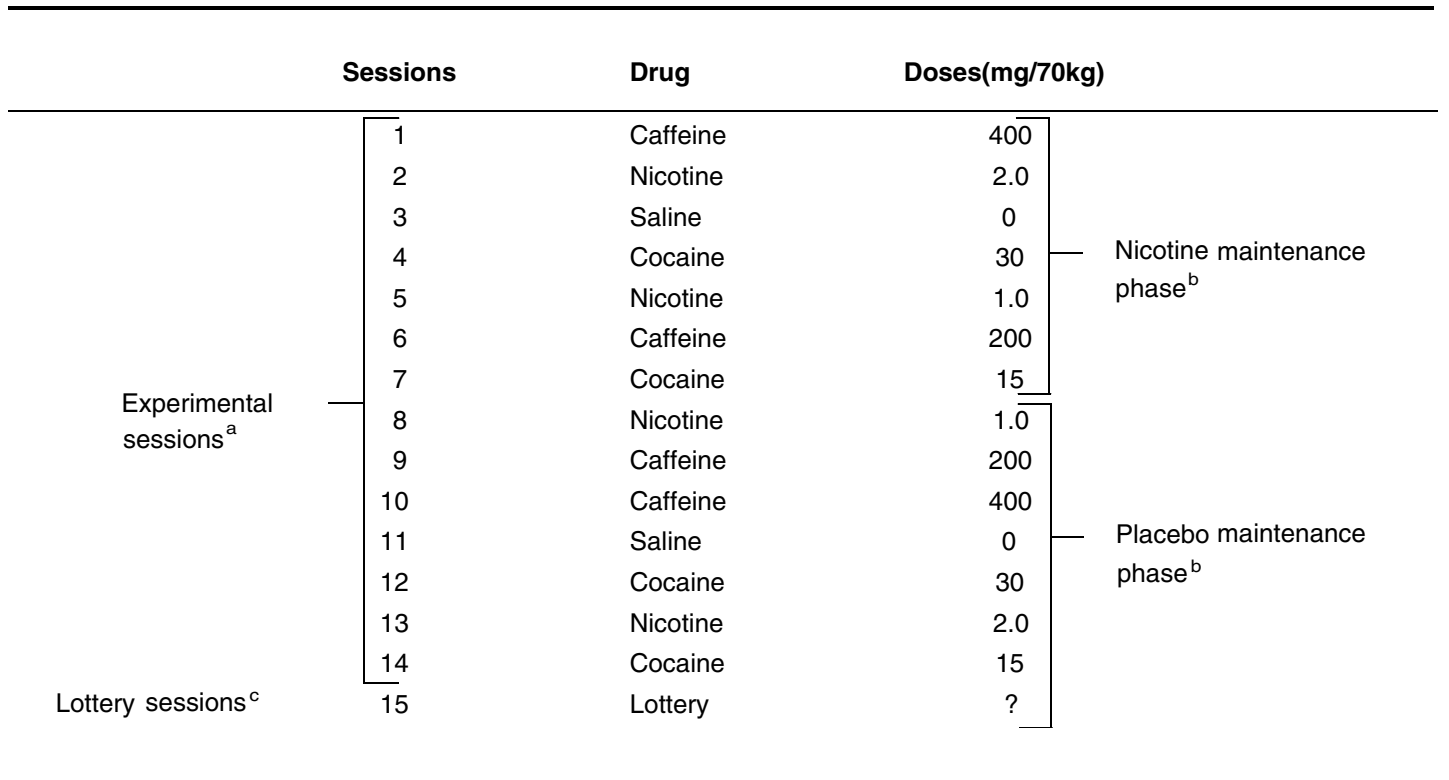

\footnotetext{
${ }^{a}$ In experimental sessions (sessions I-14), participants were exposed to the seven dose conditions twice (once during sessions I-7 and again during sessions 8-14). Sequence of dose conditions was mixed within and across participants.

${ }^{b}$ Four of the participants received the nicotine maintenance phase first, and five participants received the placebo maintenance phase first.

'Lottery session (session 15) were conducted under the same nicotine or placebo maintenance phase that was scheduled for sessions 8-14.
}

The other four participants were exposed in the reverse order.

During the 14 experimental sessions, subjects were exposed to seven intravenous dose conditions (placebo; cocaine $15,30 \mathrm{mg} / 70 \mathrm{~kg}$; caffeine $200,400 \mathrm{mg} / 70 \mathrm{~kg}$; nicotine $1.0,2.0 \mathrm{mg} / 70 \mathrm{~kg}$ ) in each of the two phases (once during sessions 1-7 and again during sessions 8-14). Within each phase and across subjects, the sequence of intravenous dose conditions was an unsystematic mixed order (ie quasirandom). The interval between experimental sessions was at least $24 \mathrm{~h}$. To minimize potential effects (eg withdrawal or tolerance) of nicotine or other drug use before the study, participants were maintained on nicotine or placebo transdermal patches for at least 2 weeks before exposure to the first of the seven intravenous dose conditions in each phase. On the final session of the study (session 15, Lottery session), participants could receive any of the test doses of cocaine, caffeine, nicotine, or placebo depending on the outcome of the Drug vs Money Multiple-Choice Form (described below).

\section{Cigarette and Caffeine Restrictions}

Participants were not permitted to smoke tobacco cigarettes for the duration of the study. Compliance with smoking restrictions was verified via assessment of expired air carbon monoxide levels $(<5 \mathrm{ppm})$ hourly during waking hours. Compliance was excellent and it was never necessary to cancel a session due to smoking. For the duration of the study, all dietary sources of caffeine were eliminated from each participant's diet in keeping with a policy that completely restricts dietary caffeine intake for participants on the residential unit.

\section{Testing Environment}

The testing room consisted of a desk and chair for the research assistant, a large cushioned chair for the participant, a microcomputer (Apple SE 30; Apple Computer, Cupertino, CA), and a computer keyboard. The microcomputer was used to collect subjective and physiological measures. Participants were seated directly in front of the computer monitor. A research assistant was seated behind the computer with a keyboard to initiate tasks.

\section{Drug Preparation and Administration}

Transdermal patch. The nicotine or placebo transdermal patch was placed on a clean, dry, nonhairy site of the participant's upper back. Patches were covered by a taped gauze pad $\left(2^{\prime \prime} \times 4^{\prime \prime}\right.$ Band-Aid adhesive pads $)$ to prevent visual inspection and thereby increase participant blinding. The transdermal nicotine patch was the NicoDerm $\mathrm{CQ}^{\circledR}$ Transdermal System (21 mg/day; GlaxoSmithKline Consumer Healthcare). The transdermal placebo patch was of identical size to active patches but delivered no nicotine. However, because there is a slight odor associated with an active patch, each placebo patch was matched by incorporating a small strip of active patch that had no contact with the skin. After blinding, there was no indication that any volunteers tampered with the patches. Patches were changed every $24 \mathrm{~h}$ and placement sites were rotated so that a fresh site was used each day. Skin sites were not reused for a week to reduce the incidence of local dermatological symptoms.

Intravenous drugs. Each dose of nicotine was prepared by dissolving nicotine hydrogen $(+)$-tartrate powder 
(manufactured by BDH Laboratory Supplies, Poole BH15 1TD, England and distributed by Gallard-Schlesinger Industries, Inc., Carle Place, NY) in sterile saline $(0.9 \%$ sodium chloride). Each dose of caffeine consisted of caffeine and sodium benzoate injection, USP $(125 \mathrm{mg} / \mathrm{ml}$ each; American Regent Laboratories, Inc. Shirley, NY) diluted with sterile water. Each dose of cocaine was prepared by dissolving cocaine $\mathrm{HCl}$ powder (Mallinckrodt Inc., St Louis, $\mathrm{MO})$ in saline $(0.9 \%$ sodium chloride). All drug solutions were manipulated aseptically under a horizontal laminar flow hood and individually filtered through a $0.22-\mu$ millipore filter (Millipore Products Division, Bedford, MA) into a sterile pyrogen-free vial. Doses are expressed as the cocaine, caffeine or nicotine base. Cocaine $(15$ and $30 \mathrm{mg} /$ $70 \mathrm{~kg}$ ), caffeine $(200$ and $400 \mathrm{mg} / 70 \mathrm{~kg})$, nicotine (1.0 and $2.0 \mathrm{mg} / 70 \mathrm{~kg}$ ), and placebo (sterile saline) were administered through an indwelling venous catheter in a total volume of $5 \mathrm{ml}$ over a 10 -s period. Immediately following drug injection, the catheter was flushed with $2 \mathrm{ml}$ of saline. All drugs were infused manually by a physician.

\section{Daily Session Procedures}

Experimental sessions. Experimental sessions were conducted Monday through Friday, each separated by at least $24 \mathrm{~h}$. Sessions were conducted in the afternoon and lasted approximately $90 \mathrm{~min}$ (eg $20 \mathrm{~min}$ preinjection and $60 \mathrm{~min}$ postinjection). Participants ate a low fat lunch at least $2 \mathrm{~h}$ before each session. Before the start of each session, an intravenous catheter was inserted into the participant's dominant arm. A slow drip intravenous line was maintained throughout the session. During each experimental session, a single dose of either placebo, cocaine $(15,30 \mathrm{mg} / 70 \mathrm{~kg})$, caffeine $(200,400 \mathrm{mg} / 70 \mathrm{~kg})$, or nicotine $(1.0,2.0 \mathrm{mg} / 70 \mathrm{~kg})$ was administered, as described in the study design. Physiological and subjective data were collected before each injection and at various times (described below) following each injection.

\section{Visual Analog Scales}

For all subjective measures except the Sensory Assessment Questionnaire, participants entered their responses using the computer keyboard. Subjects completed a set of 11 visual analog scales (VAS) once before drug injection and at 2-min intervals for $30 \mathrm{~min}$ after injection. Participants responded by positioning an arrow along a $100-\mathrm{mm}$ line marked from 0 'Not at all' to 100 'Extremely'. Participants were instructed to respond on each item based on the effect of the intravenous injection. The VAS consisted of the following items: 'Do you feel a rush?' 'Do you feel any drug effect?' 'Does the drug have any good effects?' 'Does the drug have any bad effects?' 'Do you like the drug?' 'How high are you?' 'How drowsy/sleepy are you?' 'How alert/ energetic are you?' 'Do you feel jittery?' 'Do you feel calm/ relaxed?', and 'Do you feel stimulated?'

\section{Pharmacological Class Identification Questionnaire}

Approximately $40 \mathrm{~min}$ after each drug injection, participants completed a pharmacological class identification questionnaire on which they were asked to select the drug class that best described which drug they had received that day. After participants selected the drug class option, the computer screen displayed the names (generic and trade) of specific drugs of that drug class. Participants then chose, from the list of specific drugs, which compound was most similar to the drug they had received that day. The drug class options and specific compounds associated with each included: sedatives or muscle relaxants (diazepam (Valium), alprazolam (Xanax), lorazepam (Ativan), triazolam (Halcion), methocarbamol (Robaxin), barbiturates, alcohol, or other), antihistamines (diphenhydramine (Benadryl), promethazine (Phenergan), or other), stimulants or weight loss medications (amphetamine, cocaine, nicotine, caffeine, methylphenidate (Ritalin), diethylpropion (Tenuate), phenmetrazine (Preludin), phenylpropanolamine (Control), or other), opiates (heroin, morphine, codeine, Percodan, methadone, or other), hallucinogens (phencyclidine (PCP), LSD, marijuana, mescaline, MDMA (Ecstacy), or other), and blank or placebo.

\section{Sensory Assessment Questionnaire}

At the end of each session, immediately following the completion of the Pharmacological Class Identification Questionnaire, participants completed the Sensory Assessment Questionnaire. Participants were asked by the research assistant to describe any unusual visions, tastes, or smells experienced during the session. The research assistant wrote the participant's response on a sensory assessment questionnaire form.

\section{Physiological Measures}

Participants were monitored continuously on a number of physiological measures including blood pressure (systolic and diastolic), heart rate, and skin temperature. Data were recorded on a minute-by-minute basis for $20 \mathrm{~min}$ before the injection and for $60 \mathrm{~min}$ after the injection. Blood pressure and heart rate were measured automatically by a Criticare noninvasive patient monitor (Criticare Systems Inc, Waukesha, WI). Skin temperature was monitored using a skinsurface thermistor (Yellow Springs Instrument Co., Yellow Springs, $\mathrm{OH}$ ) taped to the index finger of the nondominant hand. Data for each of these measures were collected and stored using the previously described microcomputer. In addition to the above physiological parameters, ECG was monitored by a staff physician before and periodically after the drug injection (CodeMaster XL Defibrillator Monitor, Hewlitt Packard, McMinnville, OR). Due to measurement problems, the skin temperature data were not interpretable and are not reported.

\section{Drug vs Money Multiple-Choice Form}

Participants completed the Drug vs Money Multiple-Choice Form approximately $45 \mathrm{~min}$ after injection (immediately after completion of the final Sensory Assessment Questionnaire). The multiple-choice procedure was developed and validated as a tool to efficiently assess drug reinforcement in humans (eg Griffiths et al, 1993, 1996). The present study used the drug vs money version of the procedure, which provides a contingency-based assessment of the 
monetary value for each drug condition (Mumford et al, 1995; Jones et al, 1999). Immediately after each session, participants completed a paper and pencil Drug vs Money Multiple-Choice Form to make 53 discrete choices between receiving or forfeiting varying amounts of money or receiving that day's drug again. Positive values were included to determine how much money participants were willing to forgo in order to receive that day's drug again. Negative values were included to determine if participants would forfeit money to avoid receiving that day's drug again (Schuh and Griffiths, 1997; Jones and Griffiths, 2003). The monetary values on the form ranged from $-\$ 20.00$ to $\$ 20.00$ and the intervals between values were symmetrical for the positive and negative values (cf. Smith et al, 2001). The data from the Multiple-Choice Form are presented as the maximum dollar amount at which participants chose drug over money. That amount is defined as the 'crossover' point.

Before beginning the study, three practice sessions were conducted to train the participants in using the MultipleChoice Form. The practice session began with the research assistant asking the subject to close his/her eyes, relax, and take a deep breath. When the participant appeared relaxed, the research assistant asked the subject to remember and describe several previous drug experiences. Specifically, the research assistant asked the participant to remember and describe taking a drug that had extremely positive subjective effects. This procedure was repeated for occasions involving moderately positive effects, no discernible effects and extremely negative effects. After each of these qualitatively different drug effects was described, subjects filled out the Multiple-Choice Form. The practice session was continued until the subject met the training criteria on the Multiple-Choice Form (ie making a single crossover point on each form and having a large positive, moderately positive, neutral, or large negative monetary crossover point in response to participants' verbal descriptions involving extremely positive, moderately positive, neutral, and extremely negative subjective effects, respectively). The practice session was repeated 3-4 days later and once more before the start of experimental sessions to ensure understanding of the procedure.

For the 14 experimental sessions, participants made a total of 742 choices (53 choices per session $\times 14$ sessions). At the completion of session 14 , subjects were given a container that held 742 chips, each with a number from 1 to 742 corresponding to each drug vs money choice made throughout the study. Participants drew one number at random. The choice corresponding to that number was then implemented on the last day of the study as the 'reinforcement' session (session 15, Lottery session). The reinforcement session is essential to ensuring that the Drug vs Money Multiple-Choice measure is based on a 'real-world' consequence. If the participant's randomly chosen number corresponded to a drug choice, then on the final session of the study, she/he received the drug associated with the particular session that corresponded with that number. If the participant's randomly chosen number corresponded to a money choice, then money was added to or subtracted from the earnings and, on the final session of the study, she/ he received a saline injection. Since the form included negative monetary values, each participant was given $\$ 20.00$ at the start of the study in case a negative monetary value was randomly chosen on the Lottery session. This was done to prevent money from being subtracted from study earnings.

\section{Data Analysis}

For physiological measures, minute-by-minute data were averaged in 2-min blocks. To examine the time-course of drug effects on the VAS and physiological measures, 2-min blocks of data from the 30-min postinjection period were graphed and visually inspected. To determine maximum effects on the VAS, data were expressed as peak scores (ie the maximum score observed over the time-course in each participant). For statistical analysis of physiological effects, data were collapsed across the 30-min postinjection period. The VAS peak effect data, the crossover point data from the Drug vs Money Multiple-Choice Form, and physiological data were analyzed using a two-factor repeated measure of variance (ANOVA). The factors in the analysis were drug condition (placebo, $15 \mathrm{mg} / 70 \mathrm{~kg}$ cocaine, $30 \mathrm{mg} / 70 \mathrm{~kg}$ cocaine, $200 \mathrm{mg} / 70 \mathrm{~kg}$ caffeine, and $400 \mathrm{mg} / 70 \mathrm{~kg}$ caffeine, $1.0 \mathrm{mg} / 70 \mathrm{~kg}$ nicotine, $2.0 \mathrm{mg} / 70 \mathrm{~kg}$ nicotine), and phase (nicotine maintenance and placebo maintenance). Planned comparisons (paired $t$-tests) for the VAS, crossover point, and physiological measures were used to compare the effects of each drug dose to placebo within each phase. In addition, to examine the effects of the nicotine maintenance phase $v s$ the placebo maintenance phase, planned comparisons were also conducted between the same drug dose in each phase (eg $2 \mathrm{mg} / 70 \mathrm{~kg}$ nicotine in the nicotine maintenance phase vs $2 \mathrm{mg} / 70 \mathrm{~kg}$ nicotine in the placebo maintenance phase). All results were considered significant when $p \leqslant 0.05$. Data from the Pharmacological Class Identification Questionnaire and the Sensory Assessment Questionnaire were not analyzed statistically.

\section{RESULTS}

\section{Visual Analog Scales}

Inspection of the timecourse data of the VAS showed that intravenous administration of cocaine, caffeine, and nicotine produced rapid onset of effects which peaked 2-4 min after injection and rapidly dissipated over the next $30 \mathrm{~min}$. Administration of all three drugs produced significant peak changes from baseline on several of the visual analog scales compared to placebo. Figure 1 presents these data for the eight measures that showed a significant main effect for drug condition. With cocaine, both doses produced significant elevations in ratings over placebo on all scales except Bad Effect in both nicotine and placebo maintenance phases. The high dose of cocaine consistently produced ratings that were approximately two-fold greater than the low dose. Planned comparisons showed that cocaine ratings were not significantly different between the nicotine and placebo maintenance phases.

With caffeine, both doses significantly increased ratings on three of the six scales (Drug Effect, Rush and Stimulated). Some doses of caffeine also produced increases in ratings of High, Alert, and Bad Effects. In contrast to cocaine, however, caffeine did not produce robust dose 

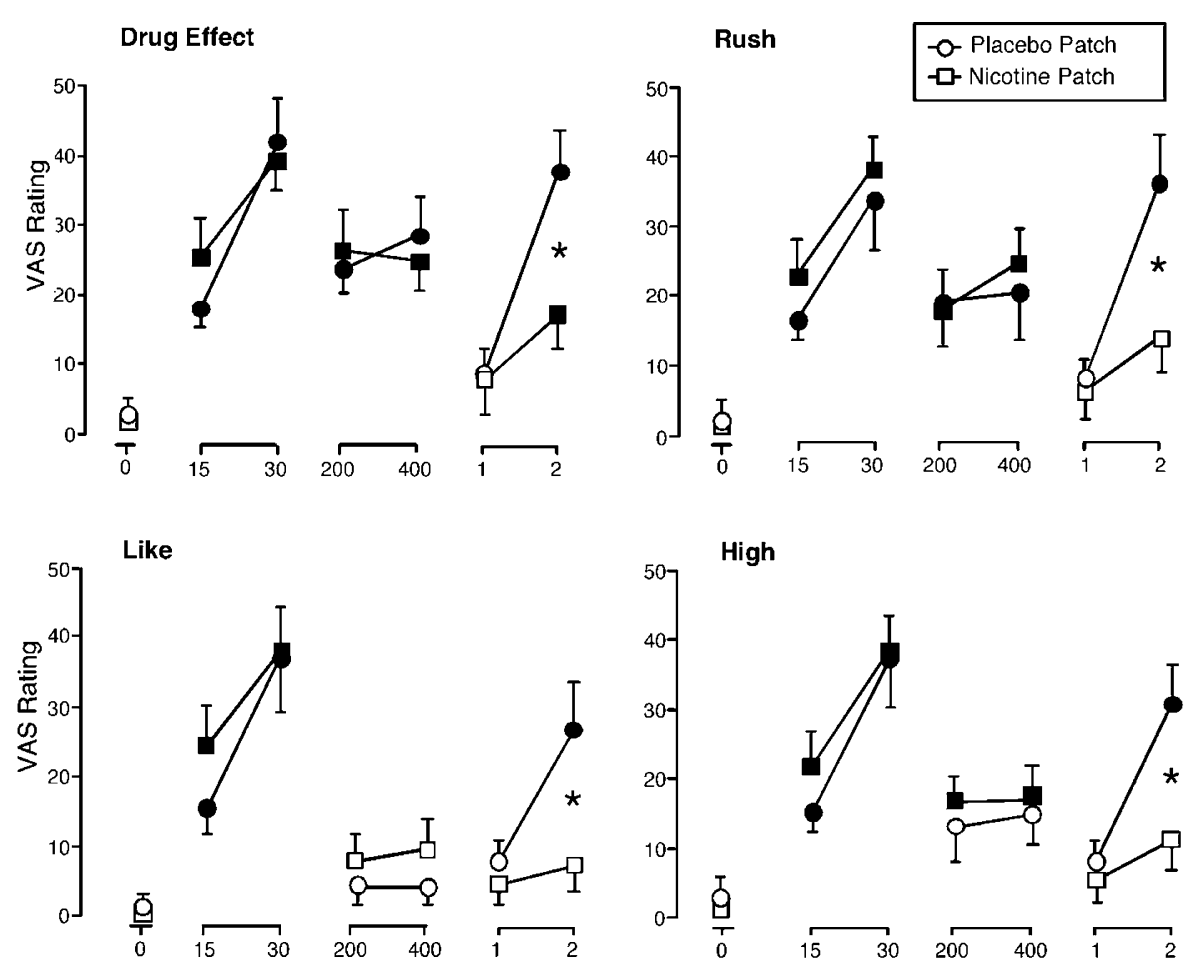

High
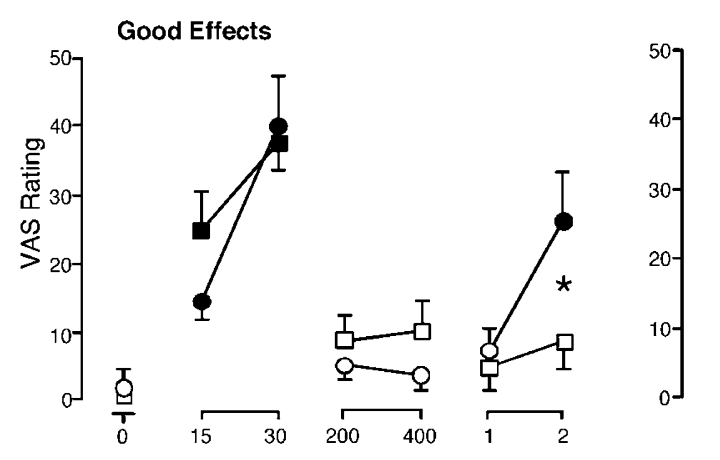

Alert
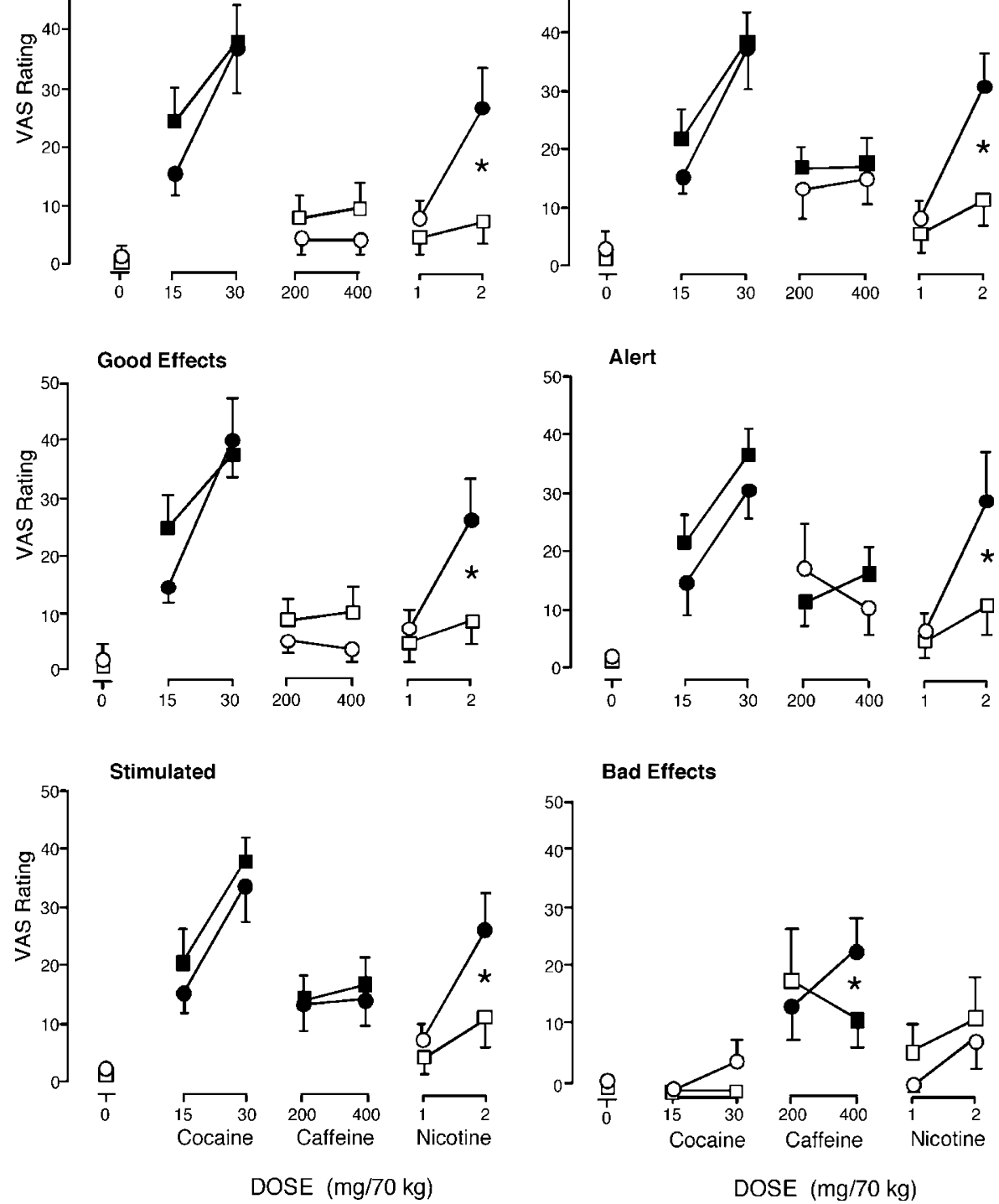

Figure I Effects of intravenous placebo, cocaine, caffeine, and nicotine on visual analog scale rating for the placebo maintenance phase ( $\bigcirc$ placebo patch) and the nicotine maintenance phase ( $\square$ nicotine patch). Data points are means $(n=9)$ of peak change from baseline. Brackets show I SEM; absence of bracket indicates SEM fell within the area of the symbol. Filled symbols indicate mean is significantly different from intravenous placebo ( $p \leqslant 0.05)$. Asterisks indicate a significant difference between the same drug dose in the nicotine maintenance and placebo maintenance phases $(p \leqslant 0.05)$.

effects (ie the high dose of caffeine did not produce ratings substantially greater than the low dose). Planned comparisons also showed that caffeine ratings were not signifi- cantly altered by the nicotine or placebo maintenance phases with the exception of one scale: the high dose of caffeine produced significantly lower ratings of Bad Effect 
during the nicotine maintenance phase compared to the placebo maintenance phase, suggesting a possible attenuation of adverse effects of caffeine by nicotine.

In contrast to cocaine and caffeine, the effects of intravenous nicotine were robustly affected by the nicotine $v s$ placebo maintenance manipulation. During the placebo maintenance phase, nicotine produced clear dose-dependent effects on seven of the eight scales, with the high-dose producing ratings approximately three-fold greater than the low dose. These dose effects were attenuated under the nicotine maintenance phase, with the high dose failing to produce effects significantly greater than placebo on all measures except Drug Effect. Planned comparisons between maintenance phases at the high dose of nicotine were significant on all measures except Bad Effects.

\section{Pharmacological Class Identification Questionnaire}

Table 2 shows the results from the pharmacological class identification questionnaire. Placebo administration was correctly identified as a blank or placebo on 100 and $78 \%$ of occasions in the nicotine and placebo maintenance phases, respectively. All three drugs were identified as a stimulant in dose-dependent fashion across both maintenance phases. Cocaine and caffeine were associated with the highest levels of stimulant identification, ranging from 78 to $100 \%$. Nicotine showed a steeper dose effect, with 44 and $78 \%$ of participants identifying the low and high dose, respectively, as a stimulant. The nicotine $v s$ placebo maintenance manipulation did not appear to influence drug identification.

\section{Sensory Assessment Questionnaire}

No participant reported experiencing unusual visions, tastes, or smells following placebo administration. Most participants (92\% overall) reported unusual tastes and/or smells following caffeine administration, with no apparent effect of either dose or maintenance condition. The unusual smells and tastes reported after intravenous caffeine administration were most often described as unpleasant (eg burnt smell, ashtray, bleach, dirty socks or feet, stale odor). In contrast to caffeine, reports of unusual tastes and/ or smells rarely occurred following administration of either cocaine or nicotine across both maintenance phases $(11 \%$ overall). Finally, in contrast to reports of unusual tastes and/or smells, reports of unusual visions rarely occurred following administration of cocaine, caffeine, or nicotine across both maintenance phases (6\% overall).

\section{Physiological Measures}

Following intravenous placebo, heart rate was modestly but significantly higher in the nicotine maintenance phase compared to the placebo maintenance phase (Figure 2). Intravenous cocaine, caffeine, and nicotine produced significant changes in several physiological measures. Intravenous cocaine generally produced significant elevations in heart rate and blood pressure, with no consistent effects of the nicotine $v s$ placebo maintenance manipulation. Compared to cocaine, intravenous caffeine, and nicotine produced more modest and less consistent elevations in these same measures. Although there were no significant differences between the nicotine and placebo maintenance phases, the significant elevations for both caffeine and nicotine occurred only under the placebo patch condition.

\section{Drug vs Money Choice}

Figure 3 shows the crossover points from the Drug vs Money Multiple-Choice Form. The placebo crossover point, which was close to zero for both maintenance phases, indicates that participants were generally neither willing to pay money to receive the injection nor forfeit money to avoid the injection. In contrast, intravenous cocaine produced significant dose-related increases in crossover point, indicating that participants were willing to pay money to receive that dose again (about $\$ 5.00$ and $\$ 11.00$ for 15 and $30 \mathrm{mg} / 70 \mathrm{~kg}$ cocaine, respectively). The crossover points with cocaine were almost identical in the nicotine and placebo maintenance phases.

Table 2 Pharmacological Class Identification

\begin{tabular}{|c|c|c|c|c|c|c|c|c|c|c|c|c|c|c|}
\hline \multirow[b]{3}{*}{ Category } & \multicolumn{7}{|c|}{ Nicotine maintenance } & \multicolumn{7}{|c|}{ Placebo maintenance } \\
\hline & \multirow{2}{*}{$\begin{array}{c}\text { Placebo } \\
0\end{array}$} & \multicolumn{2}{|c|}{$\begin{array}{l}\text { Cocaine } \\
\mathrm{mg} / 70 \mathrm{~kg}\end{array}$} & \multicolumn{2}{|c|}{$\begin{array}{l}\text { Caffeine } \\
\mathrm{mg} / 70 \mathrm{~kg}\end{array}$} & \multicolumn{2}{|c|}{$\begin{array}{l}\text { Nicotine } \\
\mathrm{mg} / 70 \mathrm{~kg}\end{array}$} & \multirow{2}{*}{$\begin{array}{c}\text { Placebo } \\
0\end{array}$} & \multicolumn{2}{|c|}{$\begin{array}{l}\text { Cocaine } \\
\mathrm{mg} / 70 \mathrm{~kg}\end{array}$} & \multicolumn{2}{|c|}{$\begin{array}{l}\text { Caffeine } \\
\mathrm{mg} / 70 \mathrm{~kg}\end{array}$} & \multicolumn{2}{|c|}{$\begin{array}{l}\text { Nicotine } \\
\mathrm{mg} / 70 \mathrm{~kg}\end{array}$} \\
\hline & & 15 & 30 & 200 & 400 & I & 2 & & 15 & 30 & 200 & 400 & $\mathbf{I}$ & 2 \\
\hline Blank or placebo & 100 & 11 & 0 & 0 & 0 & 56 & | | & 78 & 11 & 0 & | | & 0 & 56 & 0 \\
\hline Stimulant & 0 & 78 & 100 & 89 & 100 & 44 & 78 & II & 89 & 100 & 78 & 89 & 44 & 78 \\
\hline $\begin{array}{l}\text { Sedative/ } \\
\text { muscle relaxant }\end{array}$ & 0 & II & 0 & 0 & 0 & 0 & | | & I I & 0 & 0 & II & 0 & 0 & 22 \\
\hline Antihistamine & 0 & 0 & 0 & 0 & 0 & 0 & 0 & 0 & 0 & 0 & 0 & 11 & 0 & 0 \\
\hline Opiate & 0 & 0 & 0 & 0 & 0 & 0 & 0 & 0 & 0 & 0 & 0 & 0 & 0 & 0 \\
\hline Hallucinogen & 0 & 0 & 0 & | | & 0 & 0 & 0 & 0 & 0 & 0 & 0 & 0 & 0 & 0 \\
\hline
\end{tabular}

Approximately 40 min after a drug injection, participants identified the drug effect they experienced as being most similar to the effect of one of six categories of psychoactive drugs. Data are derived from the nine participants; each value in the table shows the percentage of participants selecting a given drug. 

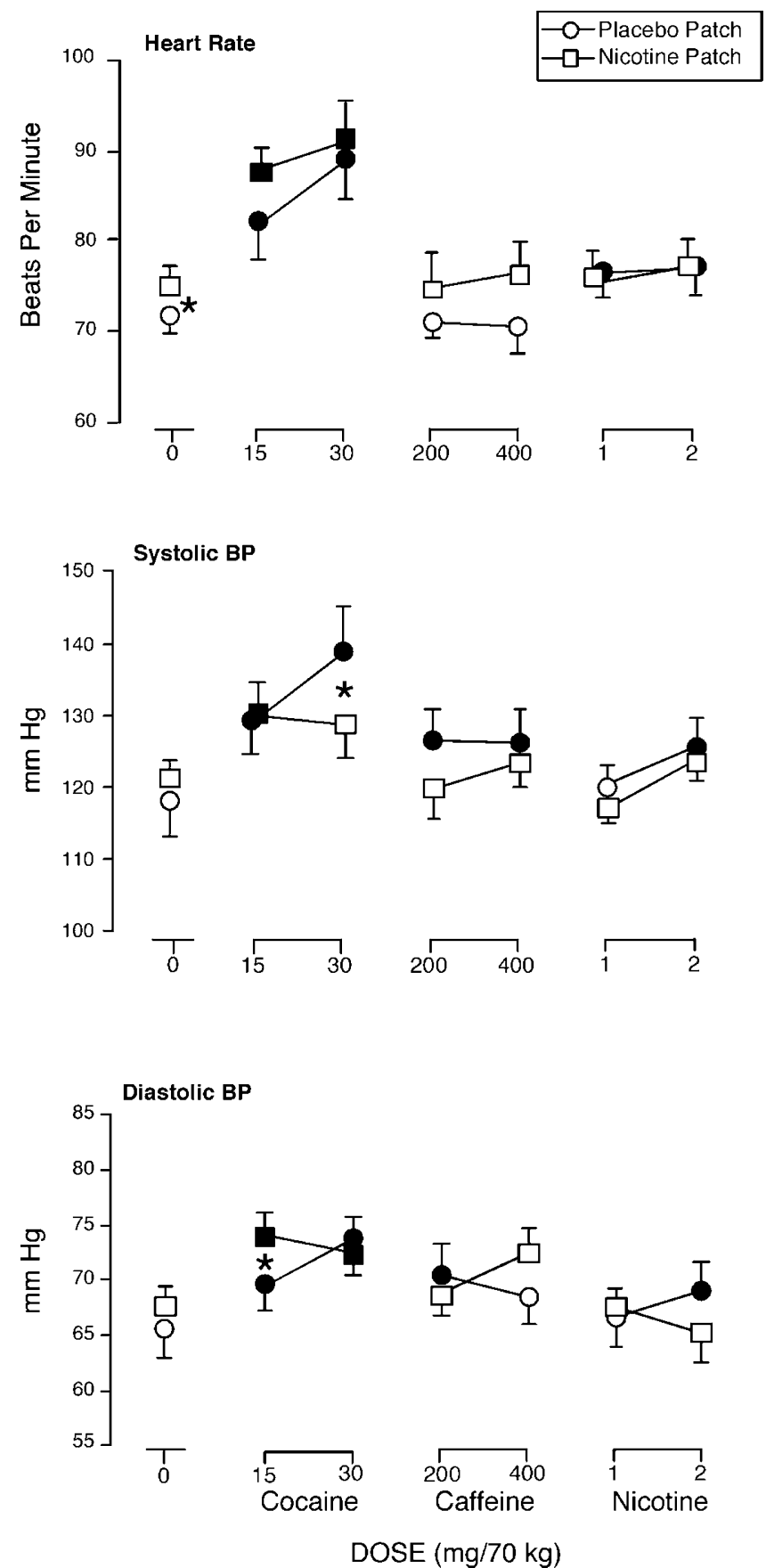

Figure 2 Effects of intravenous placebo, cocaine, caffeine, and nicotine on physiological measures for the placebo maintenance phase $(O$ placebo patch) and the nicotine maintenance phase ( $\square$ nicotine patch). Y-axes: heart rate (beats/min), systolic blood pressure $(\mathrm{mm} \mathrm{Hg})$, and diastolic blood pressure $(\mathrm{mm} \mathrm{Hg})$. Data points are means $(n=9)$; brackets show I SEM. For clarity, some data points have been slightly displaced laterally. Filled symbols indicate mean is significantly different from intravenous placebo $(p \leqslant 0.05)$. Asterisks indicate a significant difference between the same drug dose in the nicotine maintenance and placebo maintenance phases $(p \leqslant 0.05)$.

In contrast to cocaine, intravenous caffeine and nicotine did not significantly alter crossover points compared to intravenous placebo. However, a significant difference between nicotine and placebo maintenance phases on crossover point was observed with the high dose of

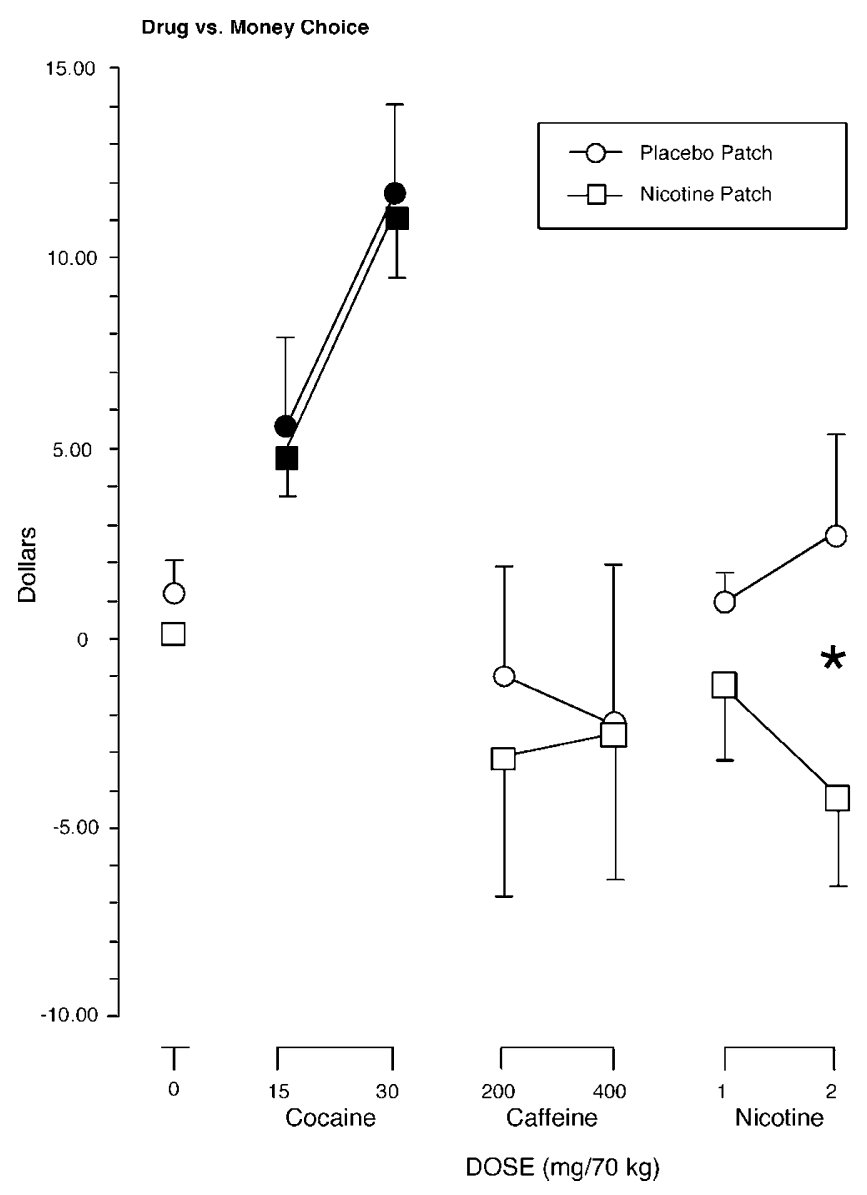

Figure 3 Effects of intravenous placebo, cocaine, caffeine, and nicotine on monetary values (cross-over points) from the Drug vs Money Multiple Choice Form. Data points are means $(n=9)$. Brackets show I SEM absence of bracket indicates SEM fell within the area of the symbol. Filled symbols indicate mean is significantly different from intravenous placebo $(p \leqslant 0.05)$. Asterisks indicate a significant difference between the same drug dose in the nicotine maintenance and placebo maintenance $(p \leqslant 0.05)$.

intravenous nicotine. This dose produced a crossover point in the nicotine maintenance phase $(-\$ 3.81)$ that was significantly lower than in the placebo maintenance phase (\$2.83), suggesting that chronic nicotine maintenance decreased the reinforcing effects of intravenous nicotine.

\section{DISCUSSION}

\section{Effects of Intravenous Cocaine}

Consistent with previous studies, intravenous cocaine was identified as a stimulant on the drug identification questionnaire and produced dose-related increases in subjective ratings indicating positive subjective effects and stimulation (Foltin and Fischman, 1991a, b; Jones et al, 1999; Donny et al, 2003).

The present study used a drug vs money multiple-choice procedure to assess the reinforcing effects of cocaine, which provides a measure of drug reinforcement that corresponds well with more conventional measures of drug reinforcement such as choice and self-administration (Griffiths et al, 1993, 1996). Intravenous cocaine produced dose-related increases in crossover points on the Drug vs Money 
Multiple-Choice Form, indicating that participants were willing to pay money to receive the drug again. These results are consistent with previous studies which used the multiple-choice procedure (Jones et al, 1999; Smith et al, 2001) and other measures of reinforcer efficacy to demonstrate the reinforcing effects of cocaine via intravenous, smoking, and intranasal routes of administration in humans (Foltin and Fischman, 1992; Hatsukami et al, 1994; Higgins et al, 1994a).

Intravenous cocaine generally produced significant elevations in heart rate and blood pressure. Similar cardiovascular effects have been reported in previous studies of intravenous cocaine administration (Foltin and Fischman, 1991a; Jones et al, 1999; Walsh et al, 2000).

\section{Effects of Nicotine Maintenance on Intravenous Cocaine}

While intravenous cocaine produced significant elevations in subjective and reinforcing effects, these effects were generally not affected by nicotine or placebo maintenance. For example, subject ratings on the visual analog scales and the pharmacological class identification questionnaire following cocaine administration did not differ between nicotine and placebo maintenance phases. The absence of an interaction between nicotine and cocaine is interesting given that nicotine and cocaine both operate on dopaminemediated pathways (Koob and Nestler, 1997; Di Chiara, 2000). More specifically, nicotine is known to affect the mesolimbic dopamine system and to modulate cocaine reinforcement via activation of nicotinic acetylcholine receptors (Di Chiara, 2000; Zachariou et al, 2001). However, it is also clear that the ability of nicotine to affect the dopamine system is complex, being modulated by various factors including different subtypes of nicotinic acetylcholine receptors, interactions among antagonistic neural pathways, and the chronicity of nicotine administration (Picciotto, 2003; Zachariou et al, 2001). Cocaine also affects the mesolimbic dopamine system, but does so primarily by blocking the dopamine transporter and limiting reuptake of dopamine once it is released (Kuhar et al, 1991; Caine, 1998). Thus, although both nicotine and cocaine effects may be mediated through dopaminergic pathways, the failure of chronic nicotine to affect the pharmacodynamic effects of cocaine in the present study may be due to these different underlying molecular mechanisms of action.

It is noteworthy that the present results appear to contrast with those of a recent study which reported that acute nicotine pretreatment attenuated cocaine effects (Kouri et al, 2001). In that study, recreational cocaine users received an intranasal cocaine dose after a $12-\mathrm{h}$ period of placebo or nicotine patch pretreatment. The results from that study showed significant attenuation of the subjective effects of cocaine, including ratings of stimulated and high. In contrast, the present results provide no evidence of attenuation of cocaine effects by nicotine. To the contrary, inspection of Figure 1 shows that, although not significantly greater, the effects of cocaine in the nicotine patch condition were often higher than in the placebo patch condition. Several methodological differences between Kouri et al (2001) and the present study could contribute to the differing results, including the transdermal nicotine dose (14 vs $21 \mathrm{mg}$, respectively), the duration of nicotine maintenance and abstinence before cocaine administration (approximately $12 \mathrm{~h}$ vs 14-25 days, respectively), the cocaine dose and route (approximately $63 \mathrm{mg}$ intranasal $v s$ 15 and $30 \mathrm{mg} / 70 \mathrm{~kg}$ intravenous, respectively) and the subject population (light cocaine users vs heavy users, respectively). Because of the chronic nature of the nicotine maintenance and abstinence manipulations in the present study, and because the high cocaine dose used in the present study approximates those doses that are normally abused, it seems unlikely that chronic cigarette smoking among cocaine abusers would affect the magnitude of subjective effects of cocaine.

\section{Effects of Intravenous Caffeine}

Intravenous caffeine was consistently identified as a stimulant on the pharmacological class identification questionnaire, with $400 \mathrm{mg} / 70 \mathrm{~kg}$ identified as a stimulant by 89 and $100 \%$ of participants during placebo and nicotine maintenance phases, respectively. These rates of stimulant identification are similar to those in a previous study (Rush et al, 1995), in which a $300 \mathrm{mg} / 70 \mathrm{~kg}$ dose of caffeine was identified as a stimulant by $95 \%$ of participants. However, rates of stimulant identification of caffeine in the present study were substantially higher than those in a study by Garrett and Griffiths (2001), in which $400 \mathrm{mg} / 70 \mathrm{~kg}$ caffeine was identified as a stimulant by only $22 \%$ of participants. It is possible that stimulant identification of caffeine is influenced by the current level of caffeine maintenance. For example, participants in the present study and in the Rush et al (1995) study, both of which demonstrated high levels of stimulant identification, were maintained on a caffeine-free diet for the duration of the study. Participants in the Garrett and Griffiths study, which demonstrated considerably lower levels of stimulant identification of caffeine, were maintained on $300 \mathrm{mg} / 70 \mathrm{~kg}$ of caffeine daily throughout the study. A study by Jones and Griffiths (2003) provides further support for the possibility that caffeine maintenance influences identification of intravenous caffeine as a stimulant. In that study, a $400 \mathrm{mg} / 70 \mathrm{~kg}$ dose of caffeine was identified as a stimulant by $78 \%$ of participants during a caffeine abstinence phase and by only $44 \%$ of participants during a caffeine maintenance phase, in which participants received $600 \mathrm{mg} / 70 \mathrm{~kg}$ daily. Considering the data across these studies, it is clear that intravenous caffeine is frequently identified as a stimulant when participants are maintained on a caffeine-free diet. It is unclear whether the attenuation of the identification of caffeine as a stimulant after caffeine maintenance reflects a tolerance mechanism (Evans and Griffiths, 1992; Griffiths and Mumford, 1995) vs some other process (cf. Jones and Griffiths, 2003).

Caffeine produced significant increases in several subjective ratings, including Drug Effect, Rush, High, Alert, and Stimulated, although these effects were not dose-dependent and were more modest and less consistent than those observed following cocaine. Intravenous caffeine also produced significant increases in ratings of Bad Effects, an effect not observed with cocaine. The profile of subjective effects and the absence of dose-dependent effects in the present study with caffeine are similar to those observed in two previous studies (Garrett and Griffiths, 2001; Jones and Griffiths, 2003). In contrast, a study by Rush et al (1995) 
showed more robust dose-related elevations in positive subjective ratings (ie increases in High, Liking, and Good Effects) using a slightly lower maximal dose of intravenous caffeine $(300 \mathrm{mg} / 70 \mathrm{~kg})$. It has previously been speculated that the robust dose-related subjective effects shown by Rush et al (1995) might be due to either the presence of nicotine (ie only a brief period of nicotine abstinence preceded the intravenous caffeine challenge) or a behavioral contrast effect. The present study showed that the presence or absence of nicotine did not influence the caffeine doseresponse function. Thus, the dose-related effects of intravenous caffeine in the Rush study are likely due to a contrast effect. That is, the Rush study evaluated only placebo and various doses of caffeine. In the present study, and in Garrett and Griffiths (2001) and Jones and Griffiths (2003), multiple doses of intravenous caffeine were administered as well as doses of nicotine and cocaine that produce pronounced ratings in subjective effects. It is possible that the subjective effects of a drug that generally produces intermediate ratings when evaluated alone will be attenuated when that drug is evaluated in the context of other drug conditions that produce much greater effects.

In the present study, intravenous caffeine was associated with reports of unusual tastes and/or smells; in contrast, intravenous placebo, cocaine and nicotine were rarely associated with such reports. These observations with caffeine, cocaine, and nicotine are consistent with previous studies (Rush et al, 1995; Garrett and Griffiths, 2001; Jones and Griffiths, 2003).

In contrast to the positive crossover points produced by cocaine, intravenous caffeine produced generally negative, although not significant, crossover points on the Drug vs Money Multiple-Choice Form. These results, which are consistent with a previous study in which the same doses of caffeine produced significant decreases in crossover points (Jones and Griffiths, 2003), suggest that participants were willing to forfeit money to avoid receiving intravenous doses of caffeine.

The modest cardiovascular effects of caffeine in the present study are also consistent with previous studies. For example, intravenous caffeine in the present study produced no significant effects on heart rate; previous studies have shown both small decreases (Rush et al, 1995; Garrett and Griffiths, 2001) and small, short-lived increases (Jones and Griffiths, 2003) in heart rate following caffeine administration. Intravenous caffeine produced inconsistent, modest increases in systolic blood pressure in the present study; previous studies have also shown increases (Rush et al, 1995), trends toward increases (Garrett and Griffiths, 2001), or no effect (Jones and Griffiths, 2003) on systolic blood pressure following caffeine administration. Finally, administration of intravenous caffeine also produced inconsistent, modest elevations in diastolic blood pressure in the present study; similar modest and short-lived increases in diastolic blood pressure have been observed in previous studies (Rush et al, 1995; Garrett and Griffiths, 2001; Jones and Griffiths, 2003).

\section{Effects of Nicotine Maintenance on Intravenous Caffeine}

The effects of intravenous caffeine were generally not affected by nicotine or placebo maintenance. For example, subject ratings on the visual analog scales, the pharmacological class identification questionnaire, and the Drug vs Money Multiple-Choice Form were not influenced by the nicotine $v s$ placebo maintenance manipulation. The only exception to this is that ratings of Bad Effects after the high dose of caffeine were modestly but significantly attenuated during nicotine maintenance. As with the subjective ratings, cardiovascular measures did not differ between the maintenance phases. These observations are interesting given that epidemiological studies have shown that cigarette smokers consume more caffeine than nonsmokers (Istvan and Matarazzo, 1984; Swanson et al, 1994). Although previous studies have shown that caffeine can enhance the reinforcing effects of nicotine (Shoaib et al, 1999; Jones and Griffiths, 2003), no study has evaluated whether nicotine enhances the reinforcing effects of caffeine. However, it is known that cigarette smoking decreases the half-life of caffeine by as much as $50 \%$ (Parsons and Neims, 1978; May et al, 1982). Thus, higher rates of caffeine consumption among cigarette smokers may be due to the faster rate of caffeine elimination. The results of the present study show that nicotine maintenance per se has no effect on the reinforcing effects of intravenous caffeine. This suggests that the elevated levels of caffeine consumption among cigarette smokers are likely due to metabolic effects of cigarette smoking rather than a pharmacological interaction between nicotine effects and caffeine reinforcement.

\section{Effects of Intravenous Nicotine}

Because the effects of intravenous nicotine were significantly attenuated in the nicotine maintenance phase, the placebo maintenance phase will be discussed first. The low and high doses of intravenous nicotine were identified as a stimulant on the pharmacological class identification questionnaire by 44 and $78 \%$ of participants, respectively, during the placebo maintenance phase. This dose-dependent increase in stimulant identification of nicotine is similar to that observed at comparable doses in previous studies (Jones et al, 1999; Garrett and Griffiths, 2001; Jones and Griffiths, 2003). The only exception to this was the study by Jones et al (1999) in which, under conditions of chronic caffeine maintenance, a low dose of nicotine (1 mg/ $70 \mathrm{~kg}$ ) was identified as a stimulant by a high proportion of individuals. However, identification of nicotine under conditions of caffeine abstinence in that study (similar to the present study) was only $22 \%$, indicating that the presence of caffeine potentiates the identification of stimulant effects of a low dose of nicotine.

During the placebo maintenance phase, intravenous nicotine produced increases in subjective ratings, including Drug Effect, Rush, Liking, High, Good Effects, Alert, and Stimulated. The profile of positive subjective effects following intravenous nicotine (ie increases in ratings of Rush, Liking, High, and Good Effects) is similar to that observed with comparable doses of nicotine in previous studies (Jones et al, 1999; Garrett and Griffiths, 2001; Jones and Griffiths, 2003). One difference between the present study and these previous reports is that intravenous nicotine did not increase subjective ratings of Bad Effects in the present study. 
The present study contributes to an understanding of possible changes in qualitative nicotine subjective effects under conditions of prolonged nicotine abstinence. Previous studies have shown reduced positive subjective effects of acute nicotine administration via gum (Hughes et al, 2000) or nasal spray (Perkins et al, 2001) in ex-smokers compared to acutely nicotine deprived (14-16 h) current smokers. These findings have been interpreted as supporting the idea that the reinforcing effects of nicotine decrease after long-term abstinence (Hughes et al, 2000; Perkins et al, 2001). The present study demonstrated robust positive subjective effects of intravenous nicotine in current smokers who were nicotine abstinent for at least 2 weeks. The qualitative and quantitative characteristics of these effects were similar to those observed in previous studies of intravenous nicotine after brief $(8 \mathrm{~h})$ periods of nicotine abstinence (Jones et al, 1999; Garrett and Griffiths, 2001; Jones and Griffiths, 2003). Thus, the current findings suggest that 2 weeks of nicotine abstinence is insufficient to alter the positive subjective effects of nicotine. Although it remains possible that durations of nicotine abstinence longer than 2 weeks are necessary for producing a decrease in the positive subjective effects of nicotine (cf. Perkins, 2002), the current findings also raise the possibility that the previously observed differences between current smokers and ex-smokers reflect differences other than duration of nicotine abstinence.

Intravenous nicotine produced modest, nonsignificant increases in crossover points on the Drug vs Money Multiple-Choice Form. These results are consistent with those from two previous studies in which, under similar conditions of caffeine abstinence, intravenous nicotine produced nonsignificant elevations in crossover point (Jones et al, 1999; Jones and Griffiths, 2003). As with the stimulant identification of nicotine, previous research has shown that crossover points after intravenous nicotine are potentiated by the presence of caffeine (Jones and Griffiths, 2003).

Finally, intravenous nicotine produced modest but inconsistent effects on cardiovascular measures in the present study. More specifically, intravenous nicotine produced small but significant elevations in heart rate. Comparable doses in previous studies produced significant short-lived (Jones et al, 1999; Garrett and Griffiths, 2001) or sustained (Jones and Griffiths, 2003) increases in heart rate following nicotine administration. In the present study, the high dose of nicotine produced small but significant increases in systolic and diastolic blood pressure. Comparable doses in previous studies produced similar modest significant and nonsignificant elevations in systolic and diastolic blood pressure following nicotine administration (Jones et al, 1999; Garrett and Griffiths, 2001; Jones and Griffiths, 2003).

\section{Effects of Nicotine Maintenance on Intravenous Nicotine}

While nicotine maintenance did not influence the stimulant identification of intravenous nicotine, there were significant differences on subjective ratings between the two maintenance phases. Nicotine maintenance significantly attenuated ratings of positive and stimulant-like effects following the high dose of intravenous nicotine. More specifically, during the nicotine maintenance phase, ratings of Drug Effect, Rush, Liking, High, Good Effects, Alert, and Stimulated were reduced to an average of 37\% (range 27$45 \%$ ) of levels during the placebo maintenance phase, with ratings on six of these seven scales no longer being significantly different from placebo. These results extend previous research showing that tolerance develops to the subjective effects of chronically administered nicotine (West and Russell, 1987; Perkins et al, 1993, 1994; Heishman and Henningfield, 2000) by demonstrating virtually complete tolerance to the effects of a high intravenous dose of nicotine under rigorous double-blind conditions.

As with the subjective ratings, crossover points for intravenous nicotine on the Drug vs Money Multiple-Choice Form were significantly affected by nicotine maintenance condition. Intravenous nicotine produced modest increases in crossover points during the placebo maintenance phase while it produced modest decreases on this measure during nicotine maintenance. While none of these changes were significantly different from placebo, crossover points for the high dose of nicotine differed significantly between maintenance phases. These results suggest that chronic nicotine maintenance reduces the reinforcing effects of intravenous nicotine. This effect may be partly attributed to the development of tolerance to the positive subjective effects of intravenous nicotine (cf. Good Effects and Liking, Figure 1), but the possibility remains that adverse effects of intravenous nicotine are enhanced during chronic nicotine maintenance (cf. Bad Effects, Figure 1). That chronic nicotine maintenance decreases the reinforcing effects of intravenous nicotine is consistent with a previous report indicating that chronic transdermal nicotine patch decreased the positive subjective effects of cigarette smoking (Levin et al, 1994).

In contrast to the significant differences between the nicotine and placebo maintenance phases on the preceding measures, there was no significant effect of the nicotine maintenance manipulation on heart rate and blood pressure in the present study. It should be noted, however, that the only significant elevations on these measures occurred during the placebo maintenance phase, which suggests a trend toward tolerance to nicotine's cardiovascular effects. The failure to demonstrate robust tolerance to the cardiovascular effects of nicotine is consistent with previous studies (Perkins et al, 1994; Soria et al, 1996). Also of note is the observation that, following intravenous placebo, heart rate was modestly but significantly increased in the nicotine maintenance condition. These data are consistent with a previous study (Pickworth et al, 1994) showing modest elevations in heart rate during a 7-day period of transdermal nicotine administration ( $22 \mathrm{mg} /$ day). The present study suggests that development of tolerance to the heart rate-increasing effects of nicotine during chronic nicotine maintenance (and/or washout of tolerance during nicotine abstinence) is incomplete even after 2 weeks.

The present study examined the effects of chronic nicotine maintenance on the acute effects of intravenous cocaine, caffeine, and nicotine under rigorous double-blind conditions. Despite a shared dopaminergic mechanism of action, as well as evidence from epidemiological and experimental studies suggesting potential interactions, the 
present study showed no effect of chronic nicotine on the acute intravenous effects of either cocaine or caffeine. The present study also provided the most aggressive evaluation of nicotine tolerance to date by testing high intravenous challenge doses of nicotine and by inducing tolerance with long-term continuous transdermal nicotine administration. The study demonstrated virtually complete tolerance to the subjective effects as well as attenuation of the reinforcing effects of intravenous nicotine.

\section{ACKNOWLEDGEMENTS}

We gratefully thank Joe Harrison, John Yingling, Paul Nuzzo and Tim Mudric for their technical and statistical assistance; Dr David Ginn and Residential Nursing staff for medical consultation and supervision. This study was supported by NIDA Grant DA-03890.

\section{REFERENCES}

American Psychiatric Association (1994). Diagnostic and Statistical Manual of Mental Disorders, 4th edn. Washington, DC.

Budney AJ, Higgins ST, Highes JR, Bickel WK (1993). Nicotine and caffeine use in cocaine-dependent individuals. J Subst Ab 5: 117-130.

Caine SB (1998). Neuroanatomical bases of the reinforcing stimulus effects of cocaine. In: Higgins ST, Katz JL (eds). Cocaine Abuse: Behavior, Pharmacology, and Clinical Applications. Academic Press: San Diego. pp 21-49.

Di Chiara G (2000). Role of dopamine in the behavioural actions of nicotine related to addiction. Eur J Pharmacol 393: 295-314.

Donny EC, Bigelow GE, Walsh SL (2003). Choosing to take cocaine in the human laboratory: effects of cocaine dose, inter-choice interval, and magnitude of alternative reinforcement. Drug Alcohol Depend 69: 289-301.

Evans S, Griffiths RR (1992). Caffeine tolerance and choice in humans. Psychopharmacology 108: 51-59.

Foltin RW, Fischman MW (1991a). Smoked and intravenous cocaine in humans: acute tolerance, cardiovascular and subjective effects. J Pharmacol Exp Ther 257: 247-261.

Foltin RW, Fischman MW (1991b). Assessment of abuse liability of stimulant drugs in humans: a methodological survey. Drug Alcohol Depend 28: 3-48.

Foltin RW, Fischman MW (1992). Self-administration of cocaine by humans: choice between smoked and intravenous cocaine. J Pharmacol Exp Ther 261: 841-849.

Fredholm BB, Bättig K, Holmén J, Nehlig A, Zvartau EE (1999). Actions of caffeine in the brain with special reference to factors that contribute to its widespread use. Pharmacol Rev 51: 83-133.

Garrett BE, Griffiths RR (1997). The Role of dopamine in the behavioral effects of caffeine in animals and humans. Pharmacol Biochem Behav 57: 533-541.

Garrett BE, Griffiths RR (2001). Intravenous nicotine and caffeine: subjective and physiological effects in cocaine abusers. J Pharmacol Exp Ther 296: 486-494.

Griffiths RR, Mumford GK (1995). Caffeine - a drug of abuse?. In: Bloom FE, Kupfer DJ (eds). Psychopharmacology: The Fourth Generation on Progress. Raven Press: New York. pp 1699-1713.

Griffiths RR, Troisi JR, Silverman K, Mumford GK (1993). Multiple-choice procedure: an efficient approach for investigating drug reinforcement in humans. Behav Pharmacol 4: 3-13.

Griffiths RR, Rush CR, Puhala KA (1996). Validation of the multiple-choice procedure for investigating drug reinforcement in humans. Exp Clin Psychopharmacol 4: 97-106.
Hatsukami DK, Thompson TN, Pentel PR, Flygare BK, Carroll ME (1994). Self-administration of smoked cocaine. Exp Clin Psychopharmacol 2: 115-126.

Heishman SJ, Henningfield JE (2000). Tolerance to repeated nicotine administration on performance, subjective, and physiological responses in nonsmokers. Psychopharmacology 152: 321-333.

Higgins ST, Bickel WK, Hughes JR (1994a). Influence of an alternative reinforcer on human cocaine self-administration. Life Sci 55: 179-187.

Higgins ST, Budney AJ, Hughes JR, Bickel WK, Lynn M, Mortensen A (1994b). Influence of cocaine use on cigarette smoking. J Am Med Assoc 272: 1724

Hughes JR, Rose GL, Callas PW (2000). Do former smokers respond to nicotine differently from never smoker? A pilot study. Nic Tob Res 2: 255-262.

Istvan J, Matarazzo JD (1984). Tobacco, alcohol, and caffeine use: a review of their interrelationships. Psychol Bull 95: 301-326.

Jones HE, Garrett BE, Grifffiths RR (1999). Subjective and physiological effects of intravenous nicotine and cocaine in cigarette smoking cocaine abusers. J Pharmacol Exp Ther 288: 188-197.

Jones HE, Griffiths RR (2003). Oral caffeine maintenance potentiates the reinforcing and stimulant subjective effects of intravenous nicotine in cigarette smokers. Psychopharmacology 165: 280-290.

Koob GF, Nestler EJ (1997). The neurobiology of drug addiction. J Neuropsych Clin Neurosci 9: 482-497.

Kouri EM, Stull M, Lukas SE (2001). Nicotine alters some of cocaine's subjective effects in the absence of physiological or pharmacokinetic changes. Pharmacol Biochem Behav 69: 209-217.

Kuhar MJ, Ritz MC, Boja JW (1991). The dopamine hypothesis of the reinforcing properties of cocaine. Trends Neurosci 14: 299-302.

Levin ED, Westman EC, Stein RM, Carnahan E, Sanchez M, Herman S et al. (1994). Nicotine skin patch treatment increases abstinence, decreases withdrawal symptoms, and attenuates rewarding effects of smoking. J Clin Psychopharmacol 14: 41-49.

May DC, Jarboe CH, VanBakel AB, Williams WM (1982). Effects of cimetidine on caffeine disposition in smokers and nonsmokers. Clin Pharmacol Ther 31: 656-661.

Mumford GK, Rush CR, Griffths RR (1995). Abecarnil and alprazolam in humans: behavioral, subjective and reinforcing effects. J Pharmacol Exp Ther 272: 570-580.

Nemeth-Coslett R, Henningfield JE, Katz J, Goldberg S (1986). Effect of cocaine on rate of cigarette smoking. Pharmacol Biochem Behav 25: 303.

Parsons WD, Neims AH (1978). Effect of smoking on caffeine clearance. Clin Pharmacol Ther 24: 40-45.

Perkins KA (2002). Chronic tolerance to nicotine in humans and its relationship to tobacco dependence. Nic Tob Res 4: 405-422.

Perkins KA, Gerlach D, Broge M, Fonte C, Wilson A (2001). Reinforcing effects of nicotine as a function of smoking status. Exp Clin Psychopharmacol 3: 243-250.

Perkins KA, Grobe JE, Epstein LH, Caggiula A, Stiller RL, Jacob RG (1993). Chronic and acute tolerance to subjective effects of nicotine. Pharmacol Biochem Behav 45: 375-381.

Perkins KA, Grobe JE, Fonte C, Goettler J, Caggiula AR, Reynolds WA et al. (1994). Chronic and acute tolerance to subjective, behavioral, and cardiovascular effects of nicotine in humans. J Pharmacol Exp Ther 270: 628-638.

Picciotto MR (2003). Nicotine as a modulator of behavior: beyond the inverted U. Trends Pharmacol Sci 24: 493-499.

Pickworth WB, Bunker EB, Henningfield JE (1994). Transdermal nicotine: reduction of smoking with minimal abuse liability. Psychopharmacology 115: 9-14. 
Reid MS, Mickalian JD, Delucchi KL, Hall SM, Berger SP (1998). An acute dose of nicotine enhances cue-induced cocaine craving. Drug Alcohol Depend 49: 95-104.

Roll JM, Higgins ST, Budney AJ, Bickel WK, Badger GJ (1996). A comparison of cocaine-dependent cigarette smokers on demographics, drug use and other characteristics. Drug Alcohol Depend 40: 195-201.

Roll JM, Higgins ST, Tidey JW (1997). Cocaine use can increase cigarette smoking: evidence from laboratory and naturalistic settings. Exp Clin Psychopharmacol 5: 263-268.

Rush CR, Sullivan JT, Griffiths RR (1995). Intravenous caffeine in stimulant drug abusers: subjective reports and physiological effects. J Pharmacol Exp Ther 273: 351-358.

Schuh KJ, Griffiths RR (1997). Caffeine reinforcement: the role of withdrawal. Psychopharmacology 130: 320-326.

Shoaib M, Swanner LS, Yasar S, Goldberg SR (1999). Chronic caffeine exposure potentiates nicotine self-administration in rats. Psychopharmacology 142: 327-333.

Smith BJ, Jones HE, Griffiths RR (2001). Physiological, subjective and reinforcing effects of oral and intravenous cocaine in humans. Psychopharmacology 156: 435-444.

Soria R, Stapleton JM, Gilson SF, Sampson-Cone A, Henningfield JE, London ED (1996). Subjective and cardiovascular effects of intravenous nicotine in smokers and nonsmokers. Psychopharmacology 128: 221-226.

Swanson JA, Lee JW, Hopp JW (1994). Caffeine and nicotine: a review of their joint use and possible interactive effects in tobacco withdrawal. Addict Behav 19: 229-256.

Tanda G, Goldberg SR (2000). Alteration of the behavioral effects of nicotine by chronic caffeine exposure. Pharmacol Biochem Behav 66: 47-64.

Walsh SL, Haberny KA, Bigelow GE (2000). Modulation of intravenous cocaine effects by chronic oral cocaine in humans. Psychopharmacology 150: 361-373.

West RJ, Russell MAH (1987). Cardiovascular and subjective effects of smoking before and after $24 \mathrm{~h}$ of abstinence from cigarettes. Psychopharmacology 92: 118-121.

Wiseman EJ, McMillan DE (1996). Combined use of cocaine with alcohol or cigarettes. Am J Drug Alcohol Abuse 22: 577-587.

Zachariou V, Caldarone BJ, Weathers-Lowin A, George TP, Elsworth JD, Roth RH et al (2001). Nicotine receptor inactivation decreases sensitivity to cocaine. Neuropsychopharmacol 24: 576-589.

Zernig G, O'Laughlin IA, Fibiger HC (1997). Nicotine and heroin augment cocaine-induced dopamine overflow in nucleus accumbens. Eur J Pharmacol 337: 1-10. 